\title{
Counter-cyclical adjustment of monetary policies and development of the real economy post the Covid-19 pandemic
}

\author{
Shuqin $\mathrm{Wu}^{1}$ \\ ${ }^{1}$ School of Management of Hubei University of Chinese Medicine, Wuhan 430065
}

\begin{abstract}
With the coronavirus kept in check, China sees an economic rebound and robust economic growth. From the angle of economics, this paper interprets China's orientation in monetary policies post the pandemic, and the prudent monetary policies are prospective, targeted policies that meet the requirements for countercyclical adjustments. The financial service providers improved in quality and efficiency, the monetary transmission efficiency was enhanced, and multiple financial service providers have jointly promoted the sustainable development of the real economy.
\end{abstract}

\section{Introduction}

The Covid-19 pandemic was a major external variable in the first half of 2020, with far-reaching impact on China's economy. The lukewarm economic performance in the first half of 2020 led the country's national economy and social development to a downturn. To address the pandemic-caused economic shock, the central government issued a series of macroeconomic policies to stimulate the economy. In terms of monetary policies, People's Bank of China downregulated the reserve ratio, reduced the medium-term lending facility (MLF) interest rate, the loan prime rate (LPR) and the reverse repo rate (RRR) to cut the financing cost and boost recovery of the real economy from the pandemic. M2 and loans and social financing capital accelerated, which indicated that the real economy achieved low-cost liquidity, enterprises received timely support during the pandemic and loose monetary policies played a supportive role in tiding enterprises over the pandemic. In October 2020, the National Bureau of Statistics revealed that the GDP of the first three quarters was 72.2786 trillion yuan, a year-on-year increase of $0.7 \%$ and a year-on-year growth rate of $4.9 \%$. Meanwhile, the newly increased investment in fixed assets (farmers excluded) is 43.6530 trillion yuan, a year-on-year increase of $0.8 \%$, and the growth rate first turned positive in the year. The total retail sales of consumer goods were 27.3324 trillion, a year-on-year decrease of $7.2 \%$ and 4.2 percent points lower than the first half of the year, with a three-quarter growth rate of $0.9 \%$, which marked the first time the growth rate turning positive in the year. The service sector has recovered, with a $4.3 \%$ growth in the third quarter and a growth rate $2.4 \%$ higher than the second quarter. It is no mean feat that China managed to maintain economic growth against the shock of the pandemic.

As the peak of the pandemic passed, China has contained the virus outbreak and maintained a stable economic growth.
It is necessary to adopt prudent monetary policies, strengthen counter-cyclical adjustment, ensure fluidity, solve constraints in financing, direct monetary credit services towards rational growth and inject vitality to the real economy.

\section{Counter-cyclical adjustment of monetary policies based on economic logic}

\subsection{Analysis of the slope of the LM curve from the perspective of economics}

The LM curve is a curve that depicts the equilibrium of the monetary market. When the actual money supply $\mathrm{M}$ is equal to the demand L, the monetary market reaches an equilibrium, and thus the LM curve is also called the monetary cure, as expressed by the equation

$$
\mathrm{y}=\frac{h r}{k}+\frac{m}{k}
$$

or

$$
\mathbf{r}=\frac{k}{h} \mathbf{y}-\frac{m}{h}
$$

Figure 1 shows an example of the LM curve when $\mathbf{y}=$ 500+500r, where the abscissa (y) represents the GDP, and the ordinate (r) represents the interest. By substituting $\mathrm{r}$ by $1 \%$, $2 \%, 3 \%$ and $4 \%$ into the equation, we could obtain the LM curve shown in Figure 1. 


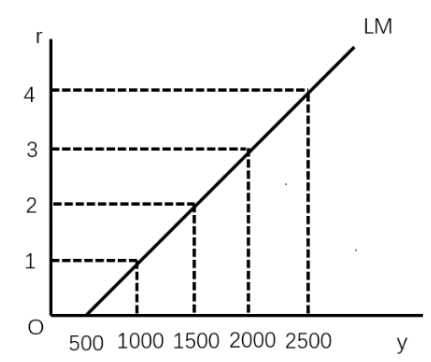

Figure 1. An example of the LM curve

From the angle of economics, the LM curve only represents a general equilibrium of the monetary market. In the real world, however, the monetary market is subject to impact of different factors, and the general equilibrium is very prone to being disrupted and new equilibriums are sought after. The economic development trajectory can be divided into three sections as per the different slopes of the LM curve: the depression section, the middle section and the classical section (Figure 2).

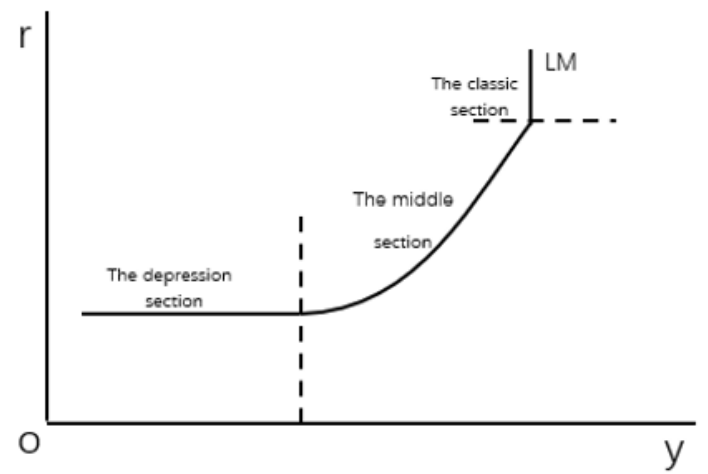

Figure 2. Three sections on the LM curve

The depression section is also called the Keynes section, within which the LM curve is nearly horizontal, indicating economic recession or depression. In this section, unemployment overwhelms the economy, the goods are hard to sell and people's living standard suffers. Typical examples include the global economic depression in the 1930s, the financial crisis that swept across Southeast Asia in 1997, the subprime crisis in America in 2008, and the current coronavirus shock. In the classic section, the LM curve was nearly vertical, which means economic overheat. This section is characterized by good employment prosepct, rising prices of goods, severe inflation, bubbles in the securities and real-estate industries. In the 1980s, the Nikkei index skyrocketed and the housing price surged in Japan, which was the result of overheated economy, and Japan paid a high price for that. China has also witnessed economic overheat in 2007 and 2008. The section between the depression section and the classic section is the middle section. From the angle of economic stability and macroeconomic regulation, the depression and classic sections are risky. In these two sections, macroeconomic regulation measures are strengthened; while in the middle section that is relatively safer, the macroeconomic regulation is alleviated.

\subsection{Post-pandemic counter-cyclical regulation of monetary policies conform to the economic logic}

At present, China's economy is on a stable rebound and stays at the depression section close to the middle section on the LM curve. This means that the monetary policies adopted before for the depression section should give way to more flexible policies. Figure 3 shows the effect of monetary policies in the middle section of the LM curve. In the figure, the economy stays in a stable growth state (the middle section of the LM curve), the monetary policies remain prudent, and counter-cyclical adjustment of the policies is performed, the central bank increases supply of money so the LM curve moves from $\mathrm{LM}_{0}$ to $\mathrm{LM}_{1}$. It shows the effect of the monetary policies has changed: in economic recession, the monetary policy curve $\mathrm{IS}_{0}$ meets with $\mathrm{LM}_{0}$ and $\mathrm{LM}_{1}$, the income rises from $\mathrm{y}_{1}$ to $\mathrm{y}_{2}$, and the income increases by $\mathrm{y}_{1} \mathrm{y}_{2}$. When the economy moves to the middle section, the monetary policy curve $\mathrm{IS}_{1}$ meets with $\mathrm{LM}_{0}$ and $\mathrm{LM}_{1}$, and the national income rises from $\mathrm{y}_{3}$ to $\mathrm{y}_{4}$, and the income increases by $\mathrm{y}_{3} \mathrm{y}_{4}$, and $\mathrm{y}_{3} \mathrm{y}_{4}$ $>\mathrm{y}_{1} \mathrm{y}_{2}$, indicating that the monetary policies employed in the middle section has injected vitality to the real economy and achieved good results.

The monetary policy effect transmission route of the counter-cyclical adjustment is as follows: the central bank increases money supply (m rises) $\rightarrow$ the interest drops ( $\mathrm{r}$ drops) $\rightarrow$ the investment into real economy increases (i increases) $\rightarrow$ the national income increases (y increases).

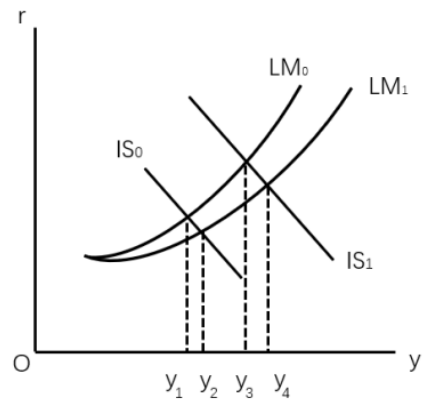

Figure 3. Effect of monetary policies in the post-pandemic "middle section"

In sum, to perform counter-cyclical adjustment of monetary policies post the pandemic is prospective and contributes to the stable and sustainable development of economy.

\section{Specific measures for post-pandemic counter-cyclical adjustment of monetary policies}

\subsection{Identifying the policy-orientation and improving the monetary policy transmission mechanism}

In the past, most monetary policies in China are dominated by quantity-based policies, supplemented by price-based policies. As the global financial market changes, it becomes necessary and urgent to strengthen price-based regulation. In 2015, the central bank of China loosens the upper limit of the 
deposit interest rate, and the monetary policy framework began to shift from the model that takes the currency quantity as the intermediate target to a model that takes the interest as the intermediate target, which indicates a shift from the quantity-based policies to price-based ones. Such a shift will improve the financial environment and smooth out the obstacles in the monetary policy transmission. Descending LPR quotation has become a major reference for banks for pricing of the loan interest, which fully reflects the policy orientation of the central bank and alleviates the supplydemand conflicts in the monetary market. The LPR has been internalized into the FTP (Funds transfer pricing) system. The hidden lower limit of the original loan interest rate was disrupted, the interest rate transmission mechanism was improved and the transmission channels were effectively straightened out.

It should be noted that to straighten out the interest rate transmission mechanism cannot be done at a stroke. After the pandemic, the orientation of China's monetary policies stay unchanged as the prudent policies still prevail, the countercyclical adjustment was performed as per the economic swings, and sharp regulation or down regulation of the interest rate is unlikely. The monetary policies will serve to ensure stable growth, adjust the structure, avoid risks, curb inflation, create new tools and strengthen implementation. In terms of the price, the potential of LPR in reforms should be given full play, the monetary policy transmission mechanism should be straightened out, and the financing cost should be downregulated to alleviate burdens on economic entities.

\subsection{Releasing monetary policies that are prospective, accurate, effective, coordinative and sustainable}

Prospective: when designing monetary policies, the policymakers should assess the domestic and international situations, the economic recovery conditions and hidden risks in a holistic manner to control the strength of the policies. Accurate: policy-makers should make full use of tools like re-lending, re-discount, targeted cuts to required reserve ratios that benefit the real economy directly, guide capital investment to manufacturing enterprises, private enterprises and small- and micro-enterprises, avoid arbitrage, invigorate real economy and ensure economic stability. Effective: policy-makers should continue clear up obstacles in policy transmission channels, deepen reforms in the LPR mechanism, orderly promote marketization of the deposit interest, improve the collaboration of deposit and lending, and reduce the cost of social financing. Coordinative: monetary policies should be aligned with macroeconomic regulation policies including fiscal policies, exchange rate policies, industry policies, employment policies to provide policy support for development of real economy. Sustainable: for policies, it is not the more the merrier; rather, the key is to leave some room of improvement for future policies and thus ensure long-term development.

\subsection{Creating a financial environment favorable to high-quality economic and social development}

Real economy is the engine of healthy economic development. The evolution of the financial system is essentially to improve the service of real economy. It is necessary to deepen structural reforms on the financial supply side and create a financial environment favorable for high-quality economic and social development. The financial supervision administrations should identify the correlation between financial enterprises and economic entities, deepen structural reforms on the financial supply side, enhance the stimulus mechanism, give full play to the role of real economy in the overall economic framework. Policy-makers should create a multi-layered, wide-covering, differential and highly-efficient financial service system, guide the stateowned financial organizations to stay down to the earth, direct the focus of small- and medium-sized financial enterprises to their major business, and develop a modern financial service system that is highly adaptable, competitive, all-beneficial and operable.

Different entities in the financial market should be united and coordinated towards a joint effort to guide investment and financial support towards private enterprises, small- and micro-enterprises. The obstacles in the monetary policy transmission channels should be cleared up, the loan interest rate should be properly down-regulated to cut the cost of real economic entities. More favorable support should be made to private enterprises that follow the country's industry development strategies, focus on their own business modules and have great potential for increasing employment. Banks should increase their lending to private enterprises, smalland micro-enterprises, credit lending and manufacturing enterprises, streamline the credit approval procedures, create a financial environment in which the supply, demand and financial services are well aligned with each other, so that a new development pattern in which the domestic market and the global market promote each other.

The financial market should serve its own roles, promote the development of real economy, and thereby preclude systematic financial risks. As for the correlation between the financial market and the real economy, the latter is the receiver of the former's services, and meanwhile the foundation for the former's sustainable development.

\section{Keeping counter-cyclical adjustment within a proper range}

\subsection{Conducting market surveys to "feel the pulse" of the economy}

"Look, smell, ask and pulse-feeling" are the four techniques widely adopted in traditional Chinese medical examinations. Macroeconomic regulation is much like providing prescriptions for the economy, and whether the prescription could take effect decides the larger picture of the country's economy or even its fate. When the market fails to properly allocate resources, the government needs to intervene and the intervening policies should be properly controlled in alignment with the actual market conditions. In other words, the government should learn from the idea of traditional 
Chinese medical examination and "feel the pulse" of the market before releasing macroeconomic regulation policies.

To "feel the pulse" of the market, in-depth market surveys are needed to explore what is wrong and what the crux of the problems is. As the saying goes, "a good doctor should know where the disease is derived". To improve the economy needs first to find the root cause of the disease, which poses a challenge to the government. In order to provide a good treatment solution to the economy, the government should discard formalism and bureaucratism in market surveys, avoid unnecessary pomp and circumstance, improve the work style of the government, uphold the industrious and honest attitude at work, capture the real economic problems after the pandemic and thereby provide a basis for economic policy-making.

\subsection{Controlling financial risks to ensure long-term and stable growth}

To pursue high-quality economic development entails a proper grasp of the correlation between long-term and stable growth and financial risk control. Healthy development of real economy is the foundation for a country's long-term economic development and also the basis for curbing financial risks.

Post the pandemic, the counter-cyclical adjustment should keep the economic growth within a proper range. We should ensure economic growth while controlling the risks, giving equal importance to both. We should prevent the financial services from going away from the real economy, control the level of government loans, keep the high leverage in check, control the role that the market plays in the real estate sector, and keep a sharp eye on the leverage ratio. The central bank should make innovations on monetary policies, adjust the indicators for financial supervision, and provide more targeted guidance for capital flow.

\subsection{Grasping the volume and orientation of fluidity to make the fullest of the structural monetary policies}

After the pandemic, prudent monetary policies should be given more flexibility to put the real economy at the central stage. Different monetary policies should be properly used to ensure fluidity and realize "targeted" support for specific entities.

In terms of the total economic output, the M2 and social financing scale should be aligned with the GDP growth. Oriented regulation should be performed to guide currency credit and the financing scale towards proper growth, stabilize the macroeconomic leverage ratio, and ensure economic equilibrium.

In terms of the structure, the counter-cyclical monetary policies should comply with regular operations and realize targeted support for specific entities. During the pandemic, the policies should be oriented to support the key and weak areas of the real economy, ensure "six stability" and "six guarantees" (stability and guarantee of employment, finance, foreign trading, foreign capital, investment, expectation). Different monetary policies that serve the real economy directly should be made use jointly to guide new financial capital to SMEs, manufacturing enterprises, infrastructure construction projects, scientific innovation initiatives, and agriculture, rural areas and farmers, so that the real economy can gain vitality and sustainable development.

\section{Author information:}

Wu Shuqin (1964- ), female, Associate Professor of School of Management of Hubei University of Chinese Medicine

Research focuses: statistics, macroeconomics, monetary banking.

Tel.: 13808666508

Email: sqw6699@126.com

Corresponding address: School of Management of Hubei University of Chinese Medicine, \#1 Huangjiahu West Rd., Hongshan District, Wuhan 430065, P.R. China

\section{References}

1. Expanding the financing channels - financial innovation backs up recovery of real economy. https://www.huanqiu.com/. 2020.11.20

2. Central bank: Giving priority to recovery and sustainable development of real economy. https://www.thepaper.cn/. 2020.06.28

3. Central bank: Providing favorable monetary policies for real economy against the pandemic. http://www.zqrb.cn/. 2020.02.27

4. Yi G. Preclude the black swan and ensure stable, healthy development of the stock and bond market. https://www.thepaper.cn/. 2019.01.09

5. Wu S. Q. Thinking over China's economic transformation [M]. Wuhan University of Technology Press, 2018.08

6. Wu S. Q. Research on the time lag of macroeconomic policies based on keynesian intervention. Modern Business Trade Industry, 2017 (30).

7. He W. C. China's monetary policy, financial system reform and sustained economic growth. Contemporary Economics. 2017 (29). 